\title{
Using Small Group Learning in the Philosophy Classroom
}

\author{
ELIZABETH JELINEK \\ Christopher Newport University
}

\begin{abstract}
I advocate the use of small group learning in the philosophy classroom because it engages a broad cross-section of students and because it proves to be an effective way to teach critical thinking. In this article, I suggest small group activities that are useful for developing philosophical skills, and I propose methods for circumventing common logistical problems that can arise when implementing small group learning in the classroom. Ultimately, I show that small group learning is a pedagogically powerful and logistically feasible supplement to traditional teaching methods.
\end{abstract}

Imagine trying to learn how to swim by listening to a lecture on swimming, without ever actually getting into the water. Surely, the best way to learn how to swim is to combine verbal instruction with activity. The same is true for learning academic material: Courses that rely solely on lecture as a way of teaching the material are less effective than courses that integrate lecture with active learning methods. Among the types of active learning exercises available in the classroom, small group learning exercises are shown to offer the greatest intellectual benefits according to the research. Specifically, studies show that students in small cooperative learning groups make greater improvements in higher-level reasoning skills and retention of information than students who work alone. ${ }^{1}$

Of course, most professors already encourage active learning via open class discussion. But open class discussion has the disadvantage that it caters only to the extroverted students; at times, these students can dominate the discussion in a way that is counterproductive to the rest of the class. I have discovered that small group learning in the classroom is a useful addition to open classroom discussion because it engages a broader cross-section of students.

The pedagogical message that you as the professor send to your students when you encourage them to work in small groups is one that 
should interest philosophy professors in particular. Professor John Bean articulates this message, "As a teaching method, collaborative learning is thus powerfully symbolic in conveying to students a view of academic life as rational dialogue rather than right answers dispensed by an authority." 2 Philosophy is not merely an account of an authority's views, and nor should my class be. I do not want to teach my students that it is wrong to lie, for example, just because Kant says so, and of course, I do not want to teach them that it is wrong to lie just because $I$ say so. Rather, I want them to understand the relevant arguments and to wrestle with them. Part of the process of learning how to do this is to actively engage with the material, and one of the most effective ways to do so, as the research shows, is via small, goal-directed group learning in the classroom. By insisting that the students grapple with these arguments with their peers, I am reinforcing the idea that they are responsible for their own learning, and that this learning is best done by actively challenging ideas.

In this paper, I argue that supervised, goal-directed, small group learning is a pedagogically powerful tool that develops the types of critical thinking skills that we philosophy professors want our students to acquire in our classes, and I propose methods for implementing this tool effectively. In part 1, I discuss experimental evidence showing the benefits of group learning for the development of critical thinking skills. Then, in part 2, I suggest ways of integrating small group activities that develop common course objectives in philosophy curricula. In part 3, I identify problems that may arise with traditional methods of using groups and I suggest methods for circumventing these problems. Finally, in part 4, I share anecdotal evidence for the effectiveness of small group activities in my own philosophy courses.

\section{Part 1: Empirical Evidence}

Educational psychologists Johnson, Johnson, and Smith characterize the overwhelmingly positive research on cooperative learning as follows, "The research on cooperative learning is like a diamond. The more light you focus on it, the brighter it becomes." 3 The research on cooperative learning is unprecedented in terms of its volume and diversity. The research has been conducted over nine decades with researchers from various countries, and it has focused on students from various grade levels (elementary school to college), economic classes, ages, nationalities, and cultural backgrounds. ${ }^{4}$ Moreover, the researchers have tested cooperative learning in subjects as diverse as geography, English composition, English as a second language, mathematics, and social sciences. ${ }^{5}$ The results are consistently positive: Johnson and Johnson report that the average person who participated 
in a cooperative learning group achieved about two-thirds of a standard deviation above the average person who performed in a competitive or individualistic situation. ${ }^{6}$

The idea that small group learning is an effective pedagogical tool is not new: in 1960, Dr. Abercrombie of the University Hospital in London found that her students learned diagnostic skills more effectively when they were placed in small groups and asked to address a diagnostic problem collaboratively. ${ }^{7}$ More recent research corroborates the idea that small group learning is more effective than more traditional methods: Hillocks and Hillocks, Kahn, and Johannessen ${ }^{8}$ show that students who worked in small groups on specifically designed tasks produced more precise argumentative writing than students who were exposed only to lecture or to open class discussion methods. ${ }^{9}$

The point to emphasize here is not just that students learn better by working in small groups with their peers, but that they perform better on tasks such as argumentative writing and critical thinking-tasks that are particularly important in a philosophy class. ${ }^{10}$ For example, a study on cooperative learning among college students shows that cooperative learning groups scored higher on "items that involve analysis, synthesis, and evaluation of the concepts." 11 The studies of Johnson and Johnson showed improvements not only in students' knowledge acquisition, retention, and accuracy, but also in their creativity in problem-solving and higher-level reasoning skills.

Theorists propose numerous reasons as to why cooperative learning tends to improve these skills in particular. According to Jean Piaget, when cooperation among individuals gives rise to healthy conflict, such conflict creates a cognitive disequilibrium, which in turn causes the individuals to see their views in a new perspective. Building upon this idea, Johnson, Johnson, and Smith propose the "controversy theory," which holds that students are more likely to thoughtfully refine their position after discussing it with peers who disagree with them. ${ }^{12}$ Along these same lines, Bruner suggests that cooperative learning activities improve students' problem-solving skills because the students are exposed to different interpretations of the given topic. Students are forced to reconcile their own views with those of their peers, and ultimately, synthesize the results. ${ }^{13}$ Problem-solving skills, higher-level reasoning skills, and critical thinking skills are all types of abilities we philosophy professors aim to cultivate in our students.

\section{Part 2: Incorporating Group Learning in Philosophy Courses ${ }^{14}$}

Some professors might have a negative reaction to using group learning as a teaching method. Bean recalls a professor who objected, "Col- 
laborative learning is unethical. I would be abdicating my professional responsibilities if I deprived students of time spent with me as a teacher, especially when they are yet untrained to work independently." ${ }^{15}$ This sentiment is not uncommon. I agree with the professor that, if one were to leave the classroom and have students discuss the course material in groups, and if one were to do this entirely in lieu of any other teaching method, then one's overall approach to teaching might be considered ineffective. But this is not the method of implementation I propose here, nor is it the method cited in the research. I am arguing that group learning is a fruitful pedagogical supplement, not a substitution for other teaching methods such as lecture.

Consider the following analogy: While mastering a craft requires much practice, practice along is not sufficient; an apprentice of any craft also needs a master to model the proper technique and offer critical feedback and inspiration. Similarly, positive group interaction is not a substitute for lectures and professor-led discussions. Consider, for example, the fact that in order for a group discussion to be successful, the students need to adhere to intellectual standards such as avoiding logical fallacies, listening carefully to their group mates, and assessing the viewpoints of others accurately and precisely. The best way for them to learn what these standards are and how to embrace them in discussion is to watch you, the professor, model them in class. It is only by observing how you effectively manage discussions among the whole class that the students will learn how to manage discussions among themselves. Personally, I find it helpful to listen in on group conversations so that I can gently steer them in the right direction if they seem to be getting off track, correct misunderstandings about the material, and answer questions. The point is, just because you are not lecturing does not mean you are not teaching. By having the students engage in well-structured group work you are giving them a rich opportunity to learn skills in an effective manner.

In my experience, the ideal course is one that balances a variety of pedagogical techniques. Doing this increases the number of student learning style preferences you can reach over the course of the semester. In addition, it is advantageous to regularly introduce a change of pace from one teaching method so that you can maintain students' interest and energy. Unfortunately, there is no magical formula for how often one should use each teaching method. When deciding how to balance the teaching tools I use-lecture, full-class discussion, and small group learning - I rely on anecdotal evidence of what balance has worked in the past. I implement small group learning activities approximately every other week (six times in a twelve week semester), and I schedule the activities according to the material. For example, in my introductory ancient Greek philosophy course, I make sure that I do not use small 
group learning for the section on Parmenides, because my lecture gives information on Parmenides that is not in the text I use for the course, and given the level of my students I cannot assume that the students can figure this topic out on their own. However, I do find it effective to discuss Heraclitus in small groups; I have the groups work together to decipher Heraclitus' aphorisms. I address issues such as group size, group arrangements, and overcoming obstacles to group work in part 3.

There are a variety of types of activities you can give your groups depending on the goal of the lesson. In what follows, I describe group activities that function to develop one or more of the following competencies: (1) the ability to think critically about philosophy, (2) the ability to read philosophy critically, and (3) the ability to synthesize the material at the end of the semester.

\section{Activities for Competency \#1:}

The Ability to Think Critically about Philosophical Arguments

One outcome that I strive to achieve for all of my courses, regardless of the topic or level of the course, is that students become equipped with the ability to think critically about arguments. I use two different types of group activities that work toward this goal.

\section{“Circular Response" Activity ${ }^{16}$}

Among the first steps to learning how to engage with philosophical arguments are learning how to listen respectfully and openly to views with which you may disagree, and learning how to accurately summarize the views of others. When the topic of conversation is a controversial issue, as it often is in a philosophy class, the students can be so eager to assert their viewpoints that, as soon as they raise their hands, they stop listening to the person who is speaking. It is difficult to impress upon the students the value of listening carefully to each other during a lively classroom discussion. Unfortunately, the tendency not to listen carefully to the opposing view transfers to the students' writing: I have repeatedly found-in both upper and lower level classes - that students have not fully grasped the argument they are discussing in their papers because they are not "listening" to it carefully. Evidence of this is their failure to accurately summarize the argument. It has been my experience that when students discuss their views in small groups, everyone-even the introverted student-is encouraged to articulate his or her own view, and everyone is more apt to listen to his or her peers.

While having the students discuss the information in small groups alleviates these problems to a certain extent, it does not eliminate them altogether; one of the members of the group may just as well dominate 
the conversation within that group, and the students may just as easily fail to listen to one another. I found that the "circular response" activity, inspired by Rogers' theory of empathic listening ${ }^{17}$ and developed by Brookfield and Preskill, is effective in circumventing these problems. ${ }^{18}$ After one student expresses his or her view to the group, each group member thereafter must begin his or her comment with a summary of the views that the previous group member just expressed. Since the students know they will be expected to summarize their peers' views, they are more likely to listen to them respectfully and strive to understand them fully. Moreover, summarizing each other's views in class is good practice for summarizing the views of other philosophers in a philosophy paper.

\section{Reasons For and Against ${ }^{19}$}

A typical instruction for writing an argument-based philosophy paper is to provide legitimate reasons to support the claims articulated in the thesis statement. I have found that many beginning students, however, do not know what constitutes a "legitimate reason" to support a claim; for example, they might think that an appeal to authority or an appeal to the majority view is an acceptable form of support. While you might simply explain this to the students in class, I found that it was ineffective to simply tell the students that they need to supply legitimate arguments in support for their claims; instead, it was more useful to combine instruction with this exercise, in which they develop arguments in groups and then receive feedback from their peers and their professor about whether these arguments are legitimate and why. Many times students were misled about what constitutes a legitimate argument in ways that I had not expected. Doing the following exercise (modeled after Elbow's "Believing and Doubting Strategy") ${ }^{20}$ revealed my students' confusions to me so that I could properly address them.

First, explain to the class as a whole the criteria that an argument needs to satisfy to be considered a legitimate argument to support a claim. It might also help to list fallacies that will disqualify an argument as legitimate, such as ad hominem attacks, appeals to authority, lack of sufficient evidence, etc. While I have found that instruction on this issue is not sufficient for the students' mastery of this concept, it is nonetheless necessary; without this instruction, the students might not know where to start. Then, have the students meet in groups. Write a controversial thesis on the board (such as, "Euthanasia is wrong because it is a form of murder"), and have each group generate a list of arguments in support of the claim or against the claim. Designate which groups have to argue for the claim and which groups have to argue against the claim to ensure that at least some of the students are forced to argue for a position with which they disagree. Arguing for 
a position opposed to their own will help the students come to understand-and respect-those opposing views. After the groups generate their lists, reconvene as a whole class and call on students at random to present their groups' arguments to the entire class. Elicit feedback from the class about whether they think that the arguments presented constitute structurally good arguments in support of a claim.

It is important to emphasize to the students the goals of this exercise: One goal is to expose oneself to arguments for viewpoints that may be opposed to one's own. The second goal is to learn about what constitutes a good argument in philosophy. It is not the goal of this particular exercise to attack each other's arguments or engage in a debate. The feedback that the professor and students give to each other after a student presents his or her group's argument to the class should focus on whether the form of the argument is one that avoids fallacies and makes proper use of reason and evidence. Here it is important that the professor set the tone for the discussion, so that it remains focused on the proper form of arguments rather than on personal attacks on the students' views.

\section{Activity for Competency \#2:}

\section{The Ability to Read Philosophy Critically}

It can be difficult to gauge whether the students are doing the assigned reading, and even more difficult to gauge whether they understand this reading and what questions they have about it. While reading quizzes can be an effective way to find out whether they have done the assigned reading, reading quizzes only give you feedback about the students' ability to recall certain details that you judge to be important about the reading. Not only does this method fail to tell you what questions they might have about the material, this method fails to give you immediate feedback that you can use in the upcoming lecture. I find that a successful way to gauge whether or not the students have done the reading and to find out what questions they have about it is to use the following group activity.

\section{Generating Reading Questions}

Have each group generate two questions based on the reading. The questions can be their own points of confusion about the reading, or they can be comprehension questions that target the points that they felt were important in the reading. Some advantages of this method are that it allows the students to show that they have done the reading even if they did not understand it, it gives you the opportunity to find out what the students found confusing about the reading, and it 
requires less grading than reading quizzes do. For example, a group in my introductory level philosophy class came up with the question:

Explain Aristotle's response to the hypothetical question: "What do you mean by saying that to become just we must first do just actions and to become temperate we must first do temperate actions? For if we do what is grammatical or musical, we must already be grammarians or musicians. In the same way then, if we do what is just or temperate, we must already be just or temperate" (1105a20). ${ }^{21}$

This reading question showed me that the students had read the assigned readings, but that they found this section particularly confusing. I knew then that that was one section I needed to cover in my lecture. As this example suggests, this is a good group activity to use at the beginning of a class session as a springboard for lecture and discussion.

Activity for Competency \#3:

The Ability to Synthesize the Material at the End of the Semester

\section{Generating Exam Questions}

Research shows that an effective way to synthesize information is to generate your own questions about the material. Rothstein and Santana have found that, "When students know how to ask their own questions, they take greater ownership of their learning, deepen comprehension, and make new connections and discoveries on their own." ${ }^{22}$ A useful way to review course material without re-teaching the entire course in one review session is to have the students generate their own essay exam questions. I use this activity regardless of whether I actually intend on giving them an exam; the exercise is valuable for helping students synthesize the material I have covered.

Before assigning this group activity, I divide the material covered into however many groups I have in the class. Then, I assign each group a section of the material. Each group member must generate his or her own exam question, and then give that question to one other member of the group. That member (and each member) must then write an answer to the exam question that she or he was given by his or her teammate. The group should post their questions and answers on a Google Doc that is shared with the entire class.

In my introductory courses, students came up with questions such as, "Why is the English word 'happiness' an insufficient translation of the Greek word 'eudaimonia?' Offer a better explanation of what 'eudaimonia' means." To come up with this question, the students needed to reflect on Aristotle's ethics as a whole to see that the translation 'happiness' fails to capture everything Aristotle says about 'eudaimonia.' In my upper level courses, this activity offered the students an opportunity to 
make connections among the different philosophers we had covered over the course of the semester. For example, in my epistemology seminar, some students came up with the question, "How would a proponent of the coherence theory of justification react to Plantinga's argument that belief in God is properly basic?" The students were able to help each other synthesize the material we had covered that semester. In addition, the questions that the groups generated provided useful study questions to use in students' own preparation for the exam outside of class.

\section{Part 3: Problems with Implementing the Group Learning Method and How to Solve Them}

Many professors do not use small group learning as a pedagogical tool because of the practical problems that arise when trying to implement it in the classroom. In what follows I identify some common problems that arise and suggest ways to circumvent them.

\section{Problem \#1: One Student Does All of the Group's Work; The Others Are Freeloaders ${ }^{23}$}

One of the most common problems with group work is that one student will take on all of the work, while the others simply go along for the ride. This is especially the case if the instructor has constructed the groups so that each group consists of both higher achieving students and lower achieving students with the goal of having the higher achievers raise the level of the students who are struggling. Typically, if the group is receiving one group grade, the higher achiever will take it upon him or herself to do all the work to ensure that it is done correctly. $\mathrm{He}$ or she has no incentive to help the less prepared students, and the less prepared students have no incentive to participate in the group's efforts; after all, everyone knows that the group will receive a better grade if the higher achieving student does all of the work.

This problem stems from fact that most people are reluctant to help others unless there is something in it for them. Indeed, research shows that, for collaborative learning to be effective, there must be both "group goals" and "individual accountability"; in other words, each person must receive an explicit reward if the group succeeds, and, in addition, each person must be held accountable for his or her own work. ${ }^{24}$ Johnson and Johnson refer to this concept as "positive social interdependence," which "exists when the outcome of individuals are [positively] affected by their own and other's actions." ${ }^{25}$ Team sports provide a good example of group goals, individual accountability, and positive social interdependence at work. The group goal is to win the game, and every team member is interested in this goal because every 
team member will share part of the glory of a team win. In addition, there is individual accountability: it is in my best interest to do well because my individual performance will affect the team's chances of winning. Moreover, it is in my best interest to help my teammates improve because their performance will also affect the team's performance. ${ }^{26}$

The following is a simple exercise that incorporates both a group goal and individual accountability in the classroom: Have the group study for a quiz together, and then have each student take the quiz on his or her own for an individual score. If everyone in the group performs well on the quiz, then add a small number of bonus points to every student's individual score. The exercise requires individual accountability because each student takes the quiz on his or her own and receives an individual grade on the quiz. The activity also provides a group goal; if everyone in the group does well on the quiz, everyone in the group receives bonus points. There is now an incentive for each group member to take the time to explain concepts to group mates and to ensure that everyone in the group learns the material. ${ }^{27}$

Professor Neil Thomason suggests a variation of this exercise: Award bonus points to groups in which every group member's quiz scores in the latter half of the semester are 10 percent higher than they were in the first half. Thomason points out that an important feature of this system is that no one is penalized for being in an unsuccessful group. Moreover, the lower achieving students have the opportunity to contribute even more than the higher achieving students, because they have the potential to make the most drastic improvements in quiz scores. ${ }^{28}$

There are ways to provide group goals in an exercise without involving grades. For example, if one were to assign the "Generating Reading Questions" activity that I mentioned previously without building group goals and individual accountability into the exercise, one might find that the burden of generating the questions falls upon one student's shoulders, while the others do nothing and still take credit. To combat this potential problem, you could require each student to develop questions first on his or her own before getting into the group. This would help mitigate the problem of students failing to contribute anything to the group discussion. ${ }^{29}$

I recently asked my students if they had any ideas of how to mitigate the problem of freeloading students in group work. ${ }^{30}$ They suggested that I require each student to fill out an anonymous survey on the performance of their peers in the group. Because the students know that they will be evaluated by their peers, they have pressure to contribute fairly to the group project. Figure 1 shows the survey I used for my classes.

If the group project is graded and you assign one grade for the group, you could incorporate these surveys by increasing or decreasing 


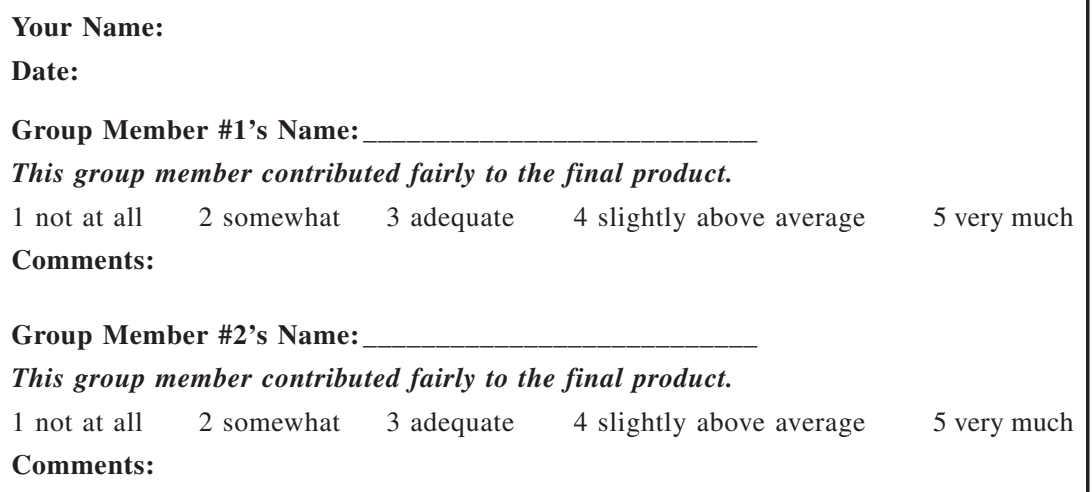

Figure 1

the grade the individual student receives based on the results of his or her peers' evaluations of him or her. Even if you do not grade the assignment, I have found that the student's knowledge that his or her peers will be evaluating his or her performance, and the knowledge that you will be reading these evaluations, is enough pressure to motivate the student to pull his or her weight in the group project.

Here is an example of an exercise that I used in my introductory level philosophy course that incorporates both group goals and individual accountability:

- Goal: To learn how to read primary sources

- Material: Books 1 and 2 of Aristotle's Nicomachean Ethics

- Group Set-up: During class time, tell the class to get into one of the configurations of the groups of three that were set up on the first day of the semester, so that each group will have different members in it than the last time groups were used in the class. (I describe a procedure for doing this in "Problem \#3.")

- Distribute a list of comprehension questions about Book 1 and 2 of Aristotle's Nicomachean Ethics to the entire class (my list consisted of twelve questions). Some of the questions I used included, "What is the relationship between virtue and nature according to Aristotle?" and "Why does Aristotle conclude that virtues are states, as opposed to feelings or capacities?"

- Assign each group two questions from the list (I assigned two questions to each of six groups).

- Individual accountability: In order to ensure that the exercise required individual accountability, I had each student answer the questions on his or her own first, before speaking to his or her group members. 
- Group goals: In order to provide an incentive for students to help all group members understand the material, I did the following: After the students discussed the answers to the questions with their group members, I called on students at random to share their group's answers. It was important that I called on them randomly, because it gave every person an incentive to make sure he or she learned the correct answer. Finally, to provide an incentive for students to spend the time explaining the answers to their peers, I told them that if every member of the group answered the assigned questions correctly on the next quiz, every member of the group would receive two bonus points on his or her quiz grade.

I avoided the problem of group members perpetuating incorrect answers to the questions by calling on the students to share their group's answers with the entire class. This gave me the opportunity to correct or expand upon the answers given by the students. The group exercise was short enough that it was easy to accomplish in a class period, without requiring the groups to meet outside of class. The problem of the freeloader was mitigated by the fact that each group member spent time answering the question by him or herself before meeting with the group. Every group member was motivated to participate in the group conversation because every group member had the potential to be called upon to share the group's answer. Moreover, group members had an incentive to teach their group mates because if everyone answered the questions correctly on the next quiz, the whole group would receive bonus points. While there was a reward for being in a successful group, no one would be penalized for being in an unsuccessful one.

\section{Problem \#2: Students Are Reluctant to Do Group Work}

Students might be resistant to the idea of working in groups for a variety of reasons. Perhaps they are simply accustomed to lecture classes and are uncomfortable with the change, or perhaps they have had negative experiences with group work in previous courses. Some might even complain that they paid to hear the expert (the professor), not their peers. Recently, I surveyed my students and asked them for specific suggestions of things professors could do to mitigate students' reluctance toward group work. They offered me the following suggestions:

\section{Explain to the students why they are being asked to do group} work. Some students reported that they assumed that professors assign group work just so that the professor can enjoy a break from teaching. The students might be more motivated to participate in group activities if they are made aware of the abundance of research that shows that collaborative learning improves critical 
thinking and problem solving skills to a significant degree. My students reported that if they knew that group work would help them learn more, they would be more willing to do it. Moreover, you can point out that most jobs require workers to solve problems and make decisions as a team. Learning how to work in groups is important for their future careers.

2. Make the case for why this assignment in particular is best approached via a collaborative group effort. For example, if the group assignment is to work through a particular philosophical concept, you can tell them that hearing an explanation put in a different way will facilitate their understanding. In the case of group discussions of controversial topics, it is important to hear perspectives that differ from one's own. For many people, discussing one's position with people who disagree can either solidify or undermine one's reasons for holding that position. Either way, it is a useful way to clarify one's own point of view. To drive this point home to your students, you could share this quote from an advice book on how to win arguments, "You want your beliefs to be true. .. . By spotting weaknesses, mistakes, and falsehoods in your own and other people's arguments, you stand a much better chance of holding to and acting on true beliefs." ${ }^{31}$ Once the students realize that group activities might help them win arguments, they might be more motivated to do them.

3. Tell the students specific strategies for making the group experience successful. One way to do this is to assign group roles (such as note-taker, presenter, moderator, time keeper) along with a rubric outlining the expectations for fulfilling this role. Another way is to require that the students engage in "group processing" once they've completed the group assignment. During "group processing," students should identify which behaviors or activities were helpful to their learning and which were detrimental. ${ }^{32}$ For the philosophy classroom in particular, I would ask them to reflect on the following questions: Are we articulating our ideas accurately? Is more precision required? Are we making any unjustified assumptions? Is our argument logical? Are our reports biased in any way? $?^{33}$ I find it helpful to walk around the classroom so that I can listen in on the groups' conversations and point out flaws in their reasoning or inaccuracies in their explanations.

I have found that an effective way to mitigate student reluctance in the beginning of the semester, before it becomes an obstacle in the class, is to set a positive tone for group work on the first day of class. Having the students do the following activity establishes the fact that 
you expect the students to be active participants in the classroom and that you value each student as an equal contributor to the conversation.

One of the most important activities to accomplish on the first day is to review the syllabus with the students so that you can give them a feel for the course structure and content and make your expectations clear. Since active learning is more effective than passive learning, why not make the introduction of the syllabus an active learning experience? I ask the students to get into groups of three, and I assign each group a section of the syllabus. Each group must read this section and explain it to the rest of the class in an engaging way. For example, the group who is responsible for the first section of the syllabus containing my office location and hours must leave the classroom and walk to my office so that they know how to find it. When they present this section to the class, they must give directions on how to find my office. The group who is responsible for the section on the texts required for my course must gather data on how many students do not yet have the textbooks and what kind of obstacles students have encountered in acquiring them (i.e., the bookstore ran out of copies). The group who is responsible for the section of the syllabus regarding the honor code must use their computers to access the websites I list in that section on what plagiarism is and why it is an offense, and then summarize their findings for the rest of the class.

I have found that the students are more likely to retain information about the syllabus when I have them engage in this activity than when I simply read the syllabus to them. This is partly because when the students know that they are expected to understand their assigned syllabus section well enough to explain it to the rest of the class, they are more likely to read it carefully. Moreover, the variety of voices and change of speakers from section to section are more likely to keep the students alert and attentive; alternatively, when they listen to just one voice (namely, the professor's) for an extended period of time, it is easier for them to tune out.

Finally, doing this activity on the first day sets the tone for the rest of the semester: It demonstrates that I emphasize active learning over passive learning, and it shows the students that I expect them to be actively responsible for their own learning. Like all group work, the activity ensures that everyone gets involved. I find that this is an effective pedagogical method for conveying the necessary information about the syllabus, but most importantly, for setting the tone for the rest of the semester.

\section{Problem \#3: Students Will Form Groups Only With Their Friends}

While I allow the students to form their own groups on the first day, the problem with having them do this each time is that, inevitably, the students will form the same groups from session to session, usually with 
people who are already in their social circle. Although I am concerned for my students' social well-being, I am more concerned that this is an obstacle to their intellectual growth: the dynamics among students' social groups often hinders their learning. For example, in one of my classes, I had a group of three students in the same social circle: one was particularly advanced and consistently well prepared and the other two were not. Of course, whenever it was time to form groups in the classroom, the three of them chose to work together. Unfortunately, the two ill-prepared student consistently took advantage of the one student by relying on him to shoulder the burden of the group's work. The social dynamics of the group were such that it would have been uncomfortable if the one student had objected.

This situation is not the only of its kind. When students are speaking to people in their social circles, they might be afraid to express their viewpoints on a particular issue if doing so reveals something personal about them that may consequently invite criticism from their friends. It might also be the case that students are afraid of articulating a correct answer in front of their friends for fear of appearing "too smart," or, vice versa, they might be afraid of expressing any answer for fear of appearing "dumb."

Another problem with having the students form their own groups is that it causes them to miss out on an intellectual opportunity. I discovered this in my philosophy of science class, which typically attracts two types of students: philosophy majors who lack a background in science, and science majors who lack a background in philosophy. If I allow the students to form their own groups, the philosophy majors typically seek out other philosophy majors, and science majors seek out other science majors. But in a philosophy of science class, there is an intellectual advantage for the students if they work with peers outside of their field of study. My solution to these problems is to use a particular method for establishing group arrangements which I describe in the next section.

\section{Problem \#4:}

\section{Putting Students into Groups Takes Up Too Much Class Time}

One common way to resolve the problems associated with students choosing their own group members is to have the students "count off," and then place all the " $1 \mathrm{~s}$ " in one group, the " $2 \mathrm{~s}$ " in another, etc. But this method does not ensure that students work with different people each time, and it tends to take up a considerable amount of class time each time you want them to do group work in class. To circumvent this, I have the students establish groups on the first day using the procedure I describe below.

In this explanation, I use a group size of three students. When deciding on group size, consider the types of activities for which you will 
be using groups. For example, if the activities are primarily centered around discussion of controversial topics, it might be disadvantageous to use smaller sized groups. This is because the fewer students in the group, the less diversity there will be among the voices, and the less likely it is for students to be exposed to viewpoints that differ from their own. Conversely, if the group is too large, it might be difficult for all group members to contribute to the discussion. I have found that groups of three are optimal for my classes. ${ }^{34}$

Here is how the procedure of establishing groups works from the perspective of a student, whom we will call John: John is first told to find two classmates with whom to form a group we will call the "Red Group." He chooses Suzy and Bob. Once he records their names, he is then told to pick two different classmates for his "Blue Group"; he picks Mary and Joe. Once he records those names, he picks two different people, Jane and Sally, for his "Green Group." He must pick different students each time.

From John's perspective, the only information he needs to record is:

Red: Suzy \& Bob

Blue: Mary \& Joe

Green: Jane \& Sally

Part of the point of this method is to have students choose different people for each color, and to have the students establish and record all of these group arrangements on the first day. This allows you to do the following later in the semester: Suppose you have your students get into their Red Groups on Monday (in this case, John will get together with Suzy and Bob). You want them to get into groups with different students on Tuesday, so on Tuesday, tell them to get into their Blue Groups (and John will get together with Mary and Joe). They can refer to their records to see who is in their Blue Group and immediately join with those people, without taking class time to create a new group arrangement.

Of course, one decision you need to make in advance of doing this exercise is how many different color configurations you would like to use throughout the semester, and this decision will depend in part on how often you would like to use groups. I discuss this issue more thoroughly in part 4. For my own courses, I estimated that, over the course of the semester, I would use group activities about six times, so I had the students create six different color configurations with three members each. This ensured that each of the six times I had the students doing group work, each student would be working with a different set of people. ${ }^{35}$

Finally, you need to consider how to maintain this data so that is can be easily accessed. I use two methods of record-keeping: On the first day of class, distribute this handout to the students, and have them record the names of their group members as they establish their groups. 
Group Arrangements for the Semester

\begin{tabular}{|l|l|l|}
\hline \multicolumn{1}{|c|}{ Red Group } \\
\hline Name: & \multicolumn{1}{c|}{ Blue Group } \\
Name: & Green Group \\
Name: & Name: \\
Name:
\end{tabular}

Figure 2

... and so on. John's will look like this:

Group Arrangements for the Semester

\begin{tabular}{|l|l|l|}
\hline \multicolumn{1}{|c|}{ Red Group } & \multicolumn{1}{c|}{ Blue Group } \\
\hline Name: Suzy & Name: Mary & $\begin{array}{l}\text { Green Group } \\
\text { Name: Jane } \\
\text { Name: Joe }\end{array}$ \\
\hline
\end{tabular}

Figure 3

$\ldots$ and so on.

In addition, I use the following data management method: After doing this exercise in class, I create a Google Doc spreadsheet with the names of each student as the column headers and the names of the group configurations as the row headers, and "share" this electronically with everyone in the class (see figure below) ${ }^{36}$ For homework after the first day of class, I ask the students to fill in the names of the members of the groups they made that day under their own names on the Google Doc. The resulting spreadsheet contains the data for everyone's group configurations. Rather than relying on the students to remember to bring the sheet of paper containing their group information, I can display the spreadsheet containing everyone's group information on the screen at the front of the classroom whenever I want the students to get into groups. I have found that using this method of setting up groups on the first day of class saves me considerable time throughout the rest of the semester and ensures that the students have the opportunity to work with different members of the class.

\begin{tabular}{|l|c|c|c|c|}
\hline & John & Mary & Dan & $\ldots$ and so on \\
\hline Red Group & Suzy & Jane & Kate & \\
\hline & Bob & Steve & Jen & \\
\hline & & & & \\
\hline Blue Group & Mary & John & David & \\
\hline & Joe & Joe & Sarah & \\
\hline & & & & \\
\hline Green Group & Jane & Kate & Suzy & \\
\hline & Sally & David & Nancy & \\
\hline
\end{tabular}

Figure 4 


\section{Problem \#5:}

\section{Students Spend Group Time Socializing Instead of Working}

The research regarding the educational benefits of small group work in the classroom specifies that the group work is structured. The most important strategy for ensuring structure is to assign a specific prompt that requires the group to generate a definable product by the end of the group meeting. For example, rather than telling the class, "Discuss the reading in your groups," tell them, "Generate a list of three points of confusion about the reading." Rather than, "Review for the exam in your groups," tell them, "Come up with two possible essay exam questions on such-and-such section of the material." I recommend writing the prompt on the board or distributing it on a handout to each of the students so that the students can refer to it and remind themselves of their goal. ${ }^{37}$

In order to ensure that the students work efficiently, I set a time limit for the group activity, and I notify them when half the time is up. The definable product that I require from the groups at the end of the session is a timed presentation by the group to the entire class. (If there is inadequate class time for each group to present, I call on one or two groups at random.) The reason for this is that students are more likely to be productive during the group conversation if they know that they will be held publicly accountable for their work. I require each member of the group to speak for an equal amount of time during this presentation in order to discourage some of the social problems that I mentioned previously, such as the issue of one group member shouldering the burden of the entire group's work. Not only does having the students present their results in front of the class pressure them to use their time efficiently during the group session, it also helps you use your time efficiently; rather than having to grade a written product from each group, you can evaluate the students' answers on the spot.

The most common way to give students an incentive to be productive during an activity is to grade them on their performance. Of course, there are problems with grading group work because it is difficult to discern the relative amount each individual has contributed. I do not embark on a full discussion of the logistics of grading group activities here; rather, I will make one small recommendation: If you do wish to grade the students on the activity, I would grade each student individually based on his or her (1) level of engagement during the activity, (2) performance during the presentation of the group's results, and (3) ability to answer questions from the class and from you following the presentation. 


\section{Part 4: Anecdotal Evidence}

I frequently assign group work in both my upper level and lower level philosophy classes. I typically use a group size of three students, and the members of the group change (using the schematic that is set up on the first day of class) each time group work is assigned. I assign group activities about six times in a twelve-week semester. This is because students have reported that this frequency achieves a good balance between group work and lecture, offering a nice "change of pace" in the classroom. I do not announce group activities in advance because I do not want to suggest to the students that they have to prepare for class any differently for group activity days than they do for regular class days. I feel strongly that the assigned group work is done only during class hours for two reasons: Logistically, it is a struggle for students to coordinate their schedules so that they can meet outside of class, especially if some of the students live off campus. Pedagogically, I find it useful for me to be able to circulate throughout the classroom during group activities and listen in on group conversations. This gives me the opportunity to offer my assistance if the group is struggling or redirect a group that has gotten off-track.

This past semester, I asked my students to reflect on their experiences with group work. In particular, I asked the students to describe both a positive experience and a negative experience they have had with group work in any academic setting, and to identify the intellectual advantages and disadvantages to doing group work in general and in my class in particular. Among the comments about positive experiences and the intellectual advantages of doing group work, students noted that it was often useful to hear alternative explanations to the ones I gave in class. For example, I had students meet in groups to try to articulate the difference between the following two sentences from Plato's Euthyphro: "It is pious because it is loved by the gods," and "It is god-loved because it is pious." Students reported that the explanations their peers gave were useful supplements to the one I had offered in class. A second positive experience that students mentioned was the group exam review ("Generating Exam Questions"). Students mentioned that it was an enjoyable way to review the material, and it prompted them to form their own study groups outside of class. In my upper level class, students felt that discussing the readings in groups was useful because they benefited from working through difficult readings together.

Common threads among the accounts of negative experiences included the problem of freeloaders in groups, the difficulty of trying to coordinate schedules to meet outside of the classroom when necessary for the assignment, and, an issue that arose in my class in particular, the problem of perpetuating misinformation. For the most 
part, I managed to mitigate the problem of freeloaders by ensuring that every group exercise required both individual accountability and a group goal (using the techniques I describe in part 3 of this paper), and I avoided the scheduling difficulty altogether by confining group activities to class hours. Unfortunately, I learned about the problem of spreading misinformation the hard way in my introductory level philosophy class. I had students generate their own exam questions and discuss the answers in their groups. The problem was that some of the students' notes were either missing or incorrect. These students presented the wrong answer to their group members, and instead of challenging this answer, the group members assumed that their peers were correct. I learned about this mishap after grading the exams and asking the students why so many of them answered a particular question incorrectly. To prevent this problem from re-occurring, I required each group to present their findings to the whole class after meeting together (as I described in part 3). This gave me the opportunity to correct any misinformation.

Because this was not a scientifically executed experiment, I cannot report on whether there was a statistically significant improvement in the students' critical thinking skills due to the group work that they did in class. According to an informal, anonymous survey, however, the majority of the students in the class responded positively to the question, "Do you feel that group work helps your learning? If so, explain." Interestingly, this is consistent with the results of a formal experimental study done on collaborative learning in a college-level basic electronics course. On the written comments on their learning experience, only two out of the forty-eight subjects studied wrote negative comments. ${ }^{38}$ While some students might remain resistant to group learning, the research — both experimental and anecdotal—shows that the majority of students benefit from this kind of learning.

While the research shows that small group learning is an effective pedagogical tool in general, I have shown how one might use this tool to fulfill the goals of a philosophy course in particular. The group activity ideas that I outlined in part 2 are particularly useful for developing the types of competencies that are important in a philosophy class. Of course, while these activities might seem nice in theory, they need to be able to be feasibly implemented in practice. In part 3, I discussed common problems with such implementation and the methods I have used to circumvent these problems successfully. Ultimately, I have found that group learning is a successful enrichment to traditional methods of teaching philosophical skills. 


\section{Notes}

I would like to thank my external reviewers for their comments and suggestions on an earlier draft of this paper, my students for their feedback on informal surveys, and Colleen Morrison and Michael Zamostny for their assistance with the research for this paper.

1. Johnson and Johnson, "Action Research," 31-32.

2. Bean, Engaging Ideas, 201.

3. Johnson, Johnson, and Smith, "Cooperative Learning Returns to College," 32.

4. Ibid.

5. Thomason, "Making Student Groups Work," 114.

6. Johnson and Johnson, "An Educational Psychology Success Story," 371.

7. Bruffee, Collaborative Learning, 13, 180.

8. Hillocks, Research on Written Composition, 184; Hillocks, Kahn, and Johannessen, "Teaching Defining Strategies as a Mode of Inquiry," 284.

9. Bean, Engaging Ideas, 186.

10. For a review of the research on small group learning, see Barkley, Cross, and Major, Collaborative Learning Techniques, 3-26.

11. Gokhale, "Collaborative Learning Enhances Critical Thinking."

12. Johnson, Johnson and Smith, "Cooperative Learning," 29.

13. Bruner, "Vygotsky."

14. For an extensive handbook on small group learning activities for the classroom, see Barkley, Cross, and Major, Collaborative Learning Techniques.

15. Bean, Engaging Ideas, 199.

16. Brookfield and Preskill, Discussion as a Way of Teaching, 55.

17. Rogers, On Becoming a Person, 331-36.

18. Brookfield and Preskill, Discussion as a Way of Teaching, 79-103.

19. For an alternative version of this activity, see Angelo and Cross, Classroom Assessment Techniques, 168-71.

20. Elbow, Writing Without Teachers, 147-92.

21. Irwin, "Nicomachean Ethics."

22. Rothstein and Santana, "Teaching Students to Ask Their Own Questions."

23. Thanks to an anonymous reviewer for encouraging me to address this issue in this paper.

24. Slavin, "Research On Cooperative Learning."

25. Johnson and Johnson, "An Educational Psychology Success Story," 371.

26. I am indebted to Neil Thomason for this analogy. Thomason, "Making Student Groups Work," 112.

27. Many scholars mention this idea, including Slavin, "Research on Cooperative Learning."

28. Thomason, "Making Student Groups Work," 116.

29. I am indebted to an anonymous reviewer for this idea.

30. Use of student data was approved by Christopher Newport University IRB \#013.031.

31. Gilbert, How to Win an Argument, 11. 
32. Johnson, Johnson, and Smith, "Cooperative Learning," 30.

33. Elder, "Collaborative Learning, Collaborative Mislearning," 45.

34. For a review of the research regarding the optimal size for small groups in the classroom, see Bruffee, Collaborative Learning, 32; and Rau and Heyl, "Humanizing the College Classroom."

35. One issue that remains is the mathematical feasibility of this approach; in other words, if the instructor picks ten colors instead of three, can the students still form different groups under each color configuration? It turns out that figuring out how many ways to partition the students without having a group repeated is mathematically complicated. It is, however, possible to put a simple lower bound on the number of configurations. If $\mathrm{N}$ is the number of students and $\mathrm{k}$ is the size of each group, then the number of possible configurations that do not repeat a group is at least $((\mathrm{N} / \mathrm{k})-1)^{(\mathrm{k}-1)}+1$. For example, if you have a class of twenty people $(\mathrm{N}=20)$ and you want them to form groups with four students each $(k=4)$, then the lower bound on the number of group configurations they can form without repeating a group is 65 .

36. When you "share" a Google doc, you must first "add" people to the doc by entering their e-mail addresses. By sharing the doc, you give each person the ability to add content to the doc and view what others have added.

37. I am indebted to Bean's discussion of how to ensure that group activities are structured. Bean, Engaging Ideas, 183-201.

38. Gokhale, "Collaborative Learning Enhances Critical Thinking."

\section{Bibliography}

Angelo, Thomas, and Patricia Cross. Classroom Assessment Techniques: A Handbook for College Teachers, 2nd ed. San Francisco: Jossey-Bass, 1993.

Barkley, Elizabeth, Patricia Cross, and Claire Major. Collaborative Learning Techniques: A Handbook for College Faculty. San Francisco: Jossey-Bass, 2005.

Bean, John. Engaging Ideas: The Professor's Guide to Integrating Writing, Critical Thinking, and Active Learning in the Classroom. San Francisco: Jossey-Bass, 2011.

Brookfield, Stephen, and Stephen Preskill. Discussion as a Way of Teaching: Tools and Techniques for Democratic Classrooms, 2nd ed. San Francisco: Jossey-Bass, 2005.

Bruffee, Kenneth. Collaborative Learning: Higher Education, Interdependence, and the Authority of Knowledge. Baltimore: Johns Hopkins University Press, 1993.

Bruner, J. "Vygotsky: An Historical and Conceptual Perspective," in Culture, Communication, and Cognition: Vygotskian Perspectives, ed. James Wertsch, 21-34. London: Cambridge University Press, 1985.

Elbow, Peter. Writing Without Teachers. New York: Oxford University Press, 1973.

Elder, Linda. “Collaborative Learning, Collaborative Mislearning," Education Week 16:25 (March 19, 1997): 45.

Gilbert, Michael A. How to Win an Argument: Surefire Strategies For Getting Your Point Across, 2nd ed. New York: John Wiley, 1996.

Gokhale, Anuradha A. "Collaborative Learning Enhances Critical Thinking," Journal of Technology Education 7:1 (1995). Accessed December 21, 2012. http://scholar.lib .vt.edu/ejournals/JTE/v7n1/gokhale.jte-v7n1.html.

Hillocks, George. Research on Written Composition: New Directions for Teaching. Urbana, Ill.: National Council of Teachers of English, 1986. 
Hillocks, George, Elizabeth Kahn, and Larry Johannessen. "Teaching Defining Strategies As a Mode of Inquiry: Some Effect on Student Writing," Research in the Teaching of English 17:3 (October 1983): 275-84.

Irwin, Terrence, trans. "Nicomachean Ethics," in Introductory Readings in Ancient Greek and Roman Philosophy, ed. C. D. C. Reeve and Patrick Lee Miller, 305-15. Cambridge, Mass.: Hackett, 2006.

Johnson, David W., and Roger T. Johnson. "Action Research: Cooperative Learning in the Science Classroom," Science and Children 24 (1986): 31-32.

"An Educational Psychology Success Story: Social Interdependence Theory and Cooperative Learning," Educational Researcher 38 (June 2009): 365-79. http://dx.doi.org/10.3102/0013189X09339057

Johnson, Roger T., David W. Johnson, and Karl A. Smith. "Cooperative Learning Returns to College," Change 30:4 (1998): 26-35. http://dx.doi.org/10.1080/00091389809602629

Rau, W. and B. S. Heyl. "Humanizing the College Classroom: Collaborative Learning and Social Organization Among Students," Teaching Sociology 18 (1990): 141-55. http://dx.doi.org/10.2307/1318484

Rogers, Carl. On Becoming a Person: A Therapist's View of Psychotherapy. Boston: Houghton Mifflin, 1961.

Rothstein, Dan, and Luz Santana. "Teaching Students to Ask Their Own Questions: One Small Change Can Yield Big Results," Harvard Education Publishing Group (September/October 2011). Accessed December 21, 2012. http://www.hepg.org/hel/article/507.

Slavin, R. E. "Research On Cooperative Learning: An International Perspective," Scandinavian Journal of Educational Research 33:4 (1989): 231-43. http://dx.doi.org/10.1080/0031383890330401

Thomason, Neil. "Making Student Groups Work," Teaching Philosophy 13:2 (1990): 111-25. http://dx.doi.org/10.5840/teachphil199013233

Vygotsky, L. S. Mind in Society: The Development of Higher Psychological Processes. Cambridge, Mass.: Harvard University Press, 1978.

Dr. Elizabeth Jelinek is an assistant professor of philosophy at Christopher Newport University. Her areas of specialization are ancient Greek philosophy and philosophy of science. She received her PhD in philosophy from Duke University. betsyjelinek@gmail.com 